\title{
What is the Effect of Changing pH on Pharmaceuticals' Sorption?
}

\author{
Petra Szabová*, Dóra Varjúová, Monika Kováčová, Josef Prousek, Igor Bodík \\ Department of Environmental Engineering, Institute of Chemical and Environmental Engineering, \\ Faculty of Chemical and Food Technology, Slovak University of Technology, Bratislava, Slovak Republic
}

Received: 10 November 2020

Accepted: 25 September 2021

\begin{abstract}
The present article aims to determine how the change in $\mathrm{pH}$ affects the adsorption efficiency of pharmaceuticals on adsorbents. Natural zeolites of various fractions and activated carbon (granular, powdered) were used as suitable and available adsorbents. A total of 102 drugs were detected at the outflow from the Devínska Nová Ves wastewater treatment plant (WWTP), and their total concentration was $12.2 \mu \mathrm{g} / \mathrm{l}$. The results of the first test $(\mathrm{pH}=7.0)$ show that the highest removal of the total drug concentration was observed in powdered activated carbon (PAC $>99 \%$ ). On the other hand, zeolites achieved the highest removal efficiency of only $52 \%$. Subsequently, the $\mathrm{pH}$ of the treated water was adjusted to 2.0, and an increase in the amount of drug removed in each of the sorbents used was observed. In granular activated carbon (GAC), a 35\% increase in total drug removal was observed. An increase in elimination was also observed for all zeolite fractions. Subsequently, the sample was adjusted to $\mathrm{pH}=12.0$, where we can observe the opposite effect. Except for PAC, all substances were removed with minimal efficiency. The elimination decreased by almost $50 \%$ for all types of zeolite fraction and GAC.
\end{abstract}

Keywords: pharmaceuticals, sorption, GAC, PAC, zeolites

\section{Introduction}

The presence of pharmaceuticals in the environment, especially in water sources, is currently the subject of a few studies. Pharmaceuticals and their metabolites enter the water environment from various sources with the discharge of municipal wastewater effluents, industrial production, agricultural run-off, etc. Their occurrence poses a high risk to aquatic ecosystems,

*e-mail: petaszabova@gmail.com but their effects on human health are considered to be rare but statistically significant [1]. This fact forced the European Union to create a watch list of the emerging compounds that include the pharmaceutical's active substance, namely, 17a-ethinylestradiol, 17 $\beta$-estradiol, estrone, erythromycin, clarithromycin, azithromycin, amoxicillin, and ciprofloxacin. The purpose of this list is to collect monitoring data and confirm the risk properties of these substances [2].

Monitoring of drugs in wastewater is relatively well mapped in many countries [3], such as Slovakia [4, 5]. The above studies show that drug concentrations in wastewater vary from unmeasurable values up to tens of $\mu \mathrm{g} / \mathrm{l}$. They also fluctuate significantly within 
individual places, during the seasons, etc. From our long-term monitoring measurements of pharmaceuticals in wastewater, we estimate that about 25-30 tons of pharmaceuticals (active pharmaceutical ingredients) enter the Slovak wastewater annually and, subsequently, a portion of them into the aquatic environment. The presence of these substances in the effluent from the wastewater treatment plant is undesirable, so it is necessary to start addressing this issue. One way to prevent the massive entry of pharmaceuticals into surface waters is to include a fourth stage of wastewater treatment.

Removal of pharmaceuticals by adsorption is one of the most promising techniques applied to current water treatment processes. Despite frequent detection and a relatively higher concentration of pharmaceuticals in sewage, their removal at full scale is quite limited $[6,7]$. Ozonation followed by the activated carbon process is increasingly used at full scale, especially in Switzerland and Germany [8]. However, intensive research is underway to find new sorption materials and optimal conditions for adsorption of pharmaceuticals from sewage $[9,10]$.

Sorption processes are among the potentially real processes that could significantly reduce the entry of drugs into the biosphere. The sorbent capacity is also a crucial factor in sorption. Adsorbents may also include sewage sludges whose surface charge is negative. In the process of wastewater treatment, various chemicals and drugs are adsorbed on the sludge, but sorption on sludge represents a low portion of total removal. The most widely used adsorbents include activated carbon and zeolites, which usually have a negative charge on the surface $[11,12]$, which supports their sorption properties.

The size of the specific adsorbent surface also plays an important role. The larger the specific surface area, the more efficient the sorption. It is also necessary to know the $\mathrm{pH}$ value for the adsorption conditions. In general, with decreasing $\mathrm{pH}$, the conditions for adsorption improve, with the $\mathrm{pH}<\mathrm{pK}_{\mathrm{a}}$ relationship when the substance is in neutral (hydrophobic) form, and with increasing $\mathrm{pH}$, the sorption conditions deteriorate as the opposite $\mathrm{pH}>\mathrm{pK}_{\mathrm{a}}$ relationship applies as the substance is in the form of an anion [11-13]. However, the effect of $\mathrm{pH}$ on adsorption has not yet been fully investigated. Therefore, it is not possible to say unequivocally why and how individual drugs behave. It is relatively complicated to determine the behaviour of drugs in changing $\mathrm{pH}$ in the case of zwitterions.

The aim of the present work is to determine the sorption behaviour of pharmaceuticals in the effluent of wastewater treatment plant when changing the $\mathrm{pH}$ of the effluent of wastewater. Three fractions of natural zeolites and two types of activated carbon were used and compared as sorption materials.

\section{Materials and Methods}

\author{
Work Methodology
}

The sorption processes were carried out with real wastewater, which was taken at the effluent from the wastewater treatment plant in Devínska Nová Ves (35 000 p.e. with negligible portion of industrial wastewater, activated sludge system with predenitrification, anaerobic sludge stabilisation).

For each sorption test (realised as triple tests), $200 \mathrm{ml}$ of treated wastewater was used, while its $\mathrm{pH}$ was adjusted to $\mathrm{pH}=2.0,7.0$ and 12.0 , respectively, using $0.05 \mathrm{M}$ sulfuric acid solution or $0.05 \mathrm{M}$ sodium hydroxide solution. Laboratory tests were performed with the following types of adsorbents: granular activated carbon (GAC), powdered activated carbon (PAC) and zeolites (three different fractions). The sorption tests were performed by weighing the required amount of activated carbon ( $1 \mathrm{~g})$ or zeolites of each fraction (5 g), and wastewater was added to the adsorbents. The sorption test was performed on an RSLAB-7 shaker (290 rpm) for $2 \mathrm{~h}$, and then the wastewater was filtered. Thus, the samples prepared were frozen at $-20^{\circ} \mathrm{C}$ and transported to an analytical laboratory at Faculty a Fisheries and Water Protection of the University of South Bohemia (Czech Republic).

\section{Zeolites}

Zeolites are defined as crystalline alkaline earth metal or alkali metal aluminosilicates which are highly hydrated [14]. They are characterised by their threedimensional tetrahedral structure $\mathrm{SiO}_{4}{ }^{4-}$ and $\mathrm{AlO}_{4}{ }^{5}$. The individual parts of the three-dimensional chain of zeolites are formed by various geometric shapes (quadrilateral, octagon, cubes, etc.), the vertices of which consist of aluminium or silicon atoms [15]. Their lattice structure allows the zeolites to act as ion exchangers and/or as selective adsorbents. When the size of the ion coincides with the size of the inlet pores into the zeolite lattice, it is easier to trap and retain the sorbed substance therein [16].

The zeolites tested were from the company Zeocem (Slovakia), and three different zeolite fractions were used:

- Coarse fraction (1.5-2.5 $\mathrm{mm})$ designation of zeolite A.

- Middle fraction (0.5-1 mm) designation of zeolite B.

- Powder fraction $(200 \mu \mathrm{m})$ labelled as zeolite.

\section{Activated Carbon}

Activated carbon as a porous carbonaceous adsorbent consists of microcrystals, which are generally composed of the following elements approximately: $\mathrm{C}-88 \%, \mathrm{H}-0.5 \%, \mathrm{~N}-0.5 \%, \mathrm{~S}-1 \%, \mathrm{O}-7 \%$ and inorganic ingredients - 3\%. It has a large internal area, which is about $500-1,500 \mathrm{~m}^{2} / \mathrm{g}$, while the pore volume 
Table 1. Specific surfaces of individual fractions of used zeolites [13], and used types of activated carbon.

\begin{tabular}{|c|c|}
\hline Zeolite fraction & Specific surface \\
\hline zeolites A & $40-42 \mathrm{~m}^{2} / \mathrm{g}$ \\
\hline zeolites B & $44-46 \mathrm{~m}^{2} / \mathrm{g}$ \\
\hline zeolites C & $53-55 \mathrm{~m}^{2} / \mathrm{g}$ \\
\hline GAC Filtrasorb 300 & $950 \mathrm{~m}^{2} / \mathrm{g}$ \\
\hline PAC NORIT SUPER SAE & $1050 \mathrm{~m}^{2} / \mathrm{g}$ \\
\hline
\end{tabular}

is $0.7-1.8 \mathrm{~cm}^{3} / \mathrm{g}$. Granular activated carbon (GAC) and powdered activated carbon (PAC) [17] are commonly used worldwide to remove micropollutants.

Two different forms of activated carbon were used in this work:

- Filtrasorb 300 granular activated carbon from the company Eurowater (Slovakia).

- Powdered activated carbon NORIT SAE SUPER from the company CABOT - activated carbon created specifically for the sorption of pollutants from wastewater.

\section{Analysis of Samples by Liquid Chromatography}

Prior to HPLC/MS/MS analysis, the samples were thawed and re-filtered through $0.20 \mu \mathrm{m}$ cellulose membrane filters to prevent column damage. Water samples were isotopically labelled with internal standards. The extraction and analysis were performed in a single step using in-line solid-phase extraction (SPE) liquid chromatography coupled with a triple quadrupole mass spectrometer (TSQ Quantiva, Thermo Fisher Scientific, USA). The analytical method and its performance have benn previously described in detail [18].

\section{Results and Discussion}

At the beginning of the experiment, drug monitoring was carried out in the outflow from the Devínska Nová Ves WWTP. From the results, we can state that 102 drugs of different therapeutic groups were detected in the effluent, of which 40 drugs were below the limit of detection. The total concentration of drugs in the monitored sample was $12,200 \mathrm{ng} / \mathrm{l}$. With a concentration above $100 \mathrm{ng} / \mathrm{l}, 14$ drugs were detected with a summary concentration of $11,105 \mathrm{ng} / \mathrm{l}$. These drugs included, for example: carbamazepine, tramadol, venlafaxine, azithromycin, clarithromycin, diclofenac, cetirizine, fexofenadine, metoprolol, telmisartan, valsartan, etc. At concentrations up to $100 \mathrm{ng} / \mathrm{l}, 43$ drugs were detected, including oxazepam, citalopram, atenolol, clindamycin, sulfamethoxazole, etc.

The first set of sorption tests was performed with real wastewater from the outflow from the Devínska

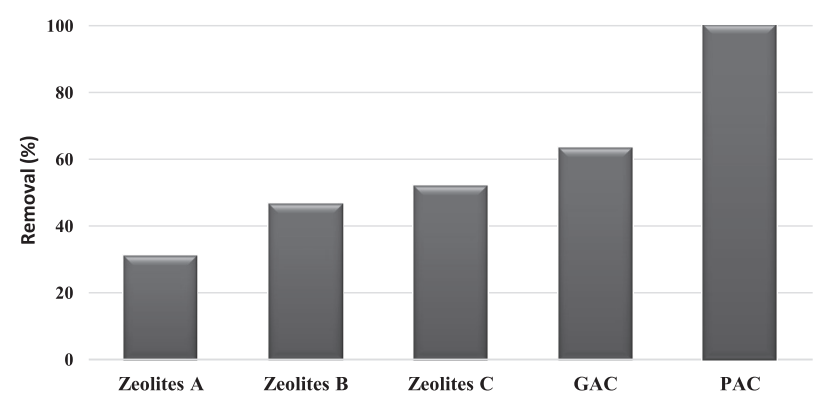

Fig. 1. Drug removal efficiencies with individual adsorbents at $\mathrm{pH}=7.0$.

Nová Ves WWTP, which had a pH value of 7.0. Zeolites of three fractions and granular and powdered activated carbon were used as sorption materials (see Table 1). Fig. 1 shows the efficiencies of removing the total drug concentration on the tested sorbents at $\mathrm{pH}=7.0$.

The efficiency of drug removal from wastewater at $\mathrm{pH}=7.0$ was quite significantly different when using zeolites and activated carbon. When zeolites were used, the drugs were removed with an efficiency of $31 \%$ to $52 \%$, and as the specific surface area of the zeolites increased, so did the sorption efficiency. Using activated carbon, we achieved $64 \%$ removal of the total drug concentration by GAC, and with powdered activated carbon, the value of the total concentration decreased to $26.6 \mathrm{ng} / \mathrm{l}$, which represents $>99 \%$ efficiency.

\section{Adsorption Trials at $p H=7.0$}

Individual drugs were also detected in the wastewater and were removed with different efficiency at $\mathrm{pH}=7.0$. An example is the antibiotic azithromycin (effluent concentration $340 \mathrm{ng} / \mathrm{l}$ ), which was removed with an efficiency of over $97 \%$ after adsorption on all types of zeolites. With the GAC type adsorbent, azithromycin was removed 'only' to $90 \%$, which is about $10 \%$ less compared with PAC. The drug verapamil had a similar course with an initial concentration of $60 \mathrm{ng} / \mathrm{l}$, which was removed after adsorption to zeolites C by $>99 \%$ efficiency. For zeolites B, the removal efficiency was $98 \%$ and, for zeolites A, only $93 \%$. For PAC and GAC, the verapamil removal efficiency is $>99 \%$.

The opposite effect of removal can be observed. For example, for the contrast agent iopromide (effluent concentration $740 \mathrm{ng} / \mathrm{l}$ ), its elimination efficiency for zeolites $\mathrm{C}$ was only 7\% (690 ng/l). With the use of zeolites B, the elimination was at $18 \%(610 \mathrm{ng} / \mathrm{l})$, and with zeolites A, they were able to remove the contrast medium only to $3 \%$. Low iopromide removal efficiencies were also observed in GAC (65\%). The highest elimination of $99.7 \%$ was achieved by PAC, but it should be noted that the PAC used was a type of pulverised coal developed for the removal of drugs from WWTPs.

Relatively low elimination efficacy was also observed with diclofenac. The originally measured 
concentration at the effluent was $1,500 \mathrm{ng} / \mathrm{l}$, and its elimination at neutral $\mathrm{pH}$ for zeolites $\mathrm{C}$ showed zero removal. For zeolites A, diclofenac removal was detected at $7 \%$ and, with zeolites B, 'only' 13\%. After completion of the sorption test with GAC and PAC adsorbents, the removal efficiency of diclofenac was relatively high: $87 \%$ for GAC and $>99 \%$ for PAC. Drugs such as sulfamethoxazole, atenolol, tramadol, and many others have similarly shown extremely low efficacy. All of these removal effectivenesss are comparable to several works by other authors $[6,7]$.

\section{Adsorption Trials at $\mathrm{pH}=2.0$ and 12.0}

Based on the findings that the adsorbents, with the exception of powdered activated carbon, do not achieve high efficiency at $\mathrm{pH}=7.0$, the $\mathrm{pH}$ was adjusted to 2.0 and 12.0 (Fig. 2) to define the effect of an acidic and basic environment on the adsorption efficiency. The deep acidic or high alkaline environment in practice at the WWTP is rare to apply from an economic point of view, so the experiment could be used only in a specific industrial wastewater (pharmaceuticals production, hospital water, etc.) before entering the sewer network.

From the data of Fig. 2, we can state that by adjusting the wastewater to $\mathrm{pH}=2.0$, the efficiency of removing the total concentration of drugs in all monitored adsorbents significantly increased. This is due to the change in the solubility of the micropollutants in wastewater [19] and the effect of the $\mathrm{pK}$ value on drug behaviour. Compared with the sorption at $\mathrm{pH}=7.0$, zeolites $\mathrm{C}$ showed up to $22 \%$ increase in sorption efficiency, a $32 \%$ increase was observed in zeolites B, and up to $44 \%$ more adsorbed drugs were seen in zeolites A. GAC at $\mathrm{pH}=2.0$ eliminated up to $99 \%$ of the total drug concentration, representing almost a 35\% improvement in sorption efficiency. In PAC, efficacy was still $>99 \%$ drug elimination.

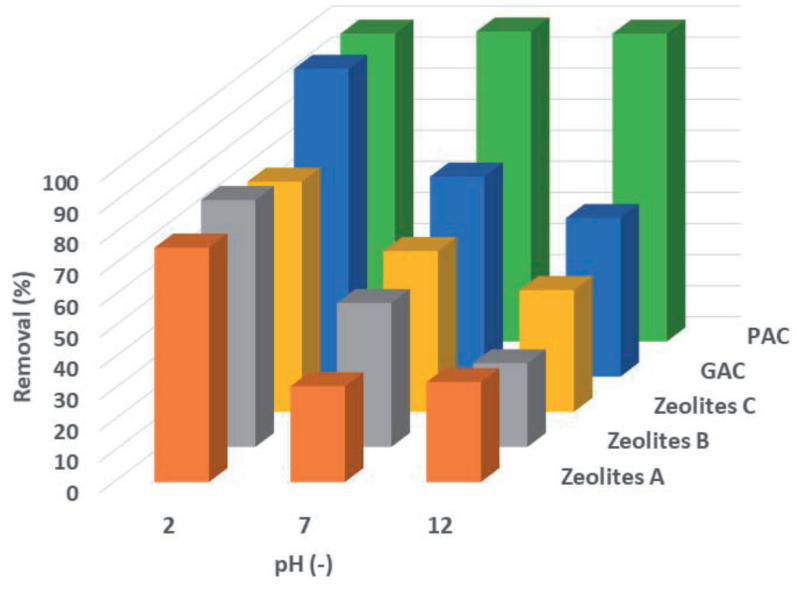

Fig. 2. Drug removal efficiencies for individual adsorbents at the monitored $\mathrm{pH}$.
When comparing the sorption efficiencies at $\mathrm{pH}=12.0$ with $\mathrm{pH}=2.0$, we can observe the opposite effect when all substances were removed with lower efficiency, while this decrease ranged from 35\% (for zeolites C) to $53 \%$ (zeolites B). Using PAC, the sorption efficiency did not show significant differences and was above $99 \%$ in all experiments.

It is clear from the results obtained that the adsorption efficiency is significantly dependent on the nature of the adsorbent, the chemical structure of the drug, and the $\mathrm{pH}$ used in the adsorption. The drugs studied contain different functional groups, which will also behave differently depending on the $\mathrm{pH}$ used. This results in the resulting charge of the whole molecule and thus the ability or inability to adsorb to different adsorbents. We can illustrate this with some examples.

\section{Removal of Individual Pharmaceutics under Different $\mathrm{pH}$ Conditions}

If we looked at the sorption of individual drugs in the monitored $\mathrm{pH}$ range in a little more detail, we could observe some relationships between the structure of the drug, $\mathrm{pH}, \mathrm{pKa}$, and binding changes in the molecule. Based on these relationships, we can generally divide all drugs into three basic groups - bases, acids, and socalled zwitterions.

Among the detected drugs, there is a group of drugs that can be classified as bases. These substances have an extremely high $\mathrm{pKa}$ value, which explains their easy (strong) ionization in aqueous solutions [20]. This group includes, for example, atenolol, caffeine, azithromycin, and many others.

A typical substance from the group of bases is atenolol. From the point of view of the structural formula of atenolol and its value $\mathrm{pK}=9.6$, it can be stated that at $\mathrm{pH}=2.0$, its protonated form $-\mathrm{NH}$, i.e. $\mathrm{NH}^{2+}$, dominates, whose sorption affinity for ionic structures of zeolites or the surface area of activated carbon is relatively high. By changing the $\mathrm{pH}$ to 7.0, the protonated form of atenolol no longer dominates, and at $\mathrm{pH}=12.0$, the molecule completely changes its character and shows rather basic properties, respectively. Thus, protonation of the molecule (at $\mathrm{pH}=2.0$ ) increased the removal efficiency of atenolol by $9 \%-41 \%$ using zeolites compared with $\mathrm{pH}=7.0$. When using zeolites, it can be stated with a certain probability that a significant part of the binding of atenolol was realised at $\mathrm{pH}=2.0$, in addition to sorption processes, also in the form of ion exchange. By increasing the $\mathrm{pH}$, the sorption efficiencies decreased significantly in all zeolite fractions. However, when using GAC and PAC, no significant difference in atenolol removal was observed with changes in $\mathrm{pH}$, which, in turn, can be explained by the predominance of rather adsorption forces between protonated atenolol and activated carbon forms. Similar changes in efficacy have been observed e.g. in ibuprofen sorption by Oh at al. [13]. 


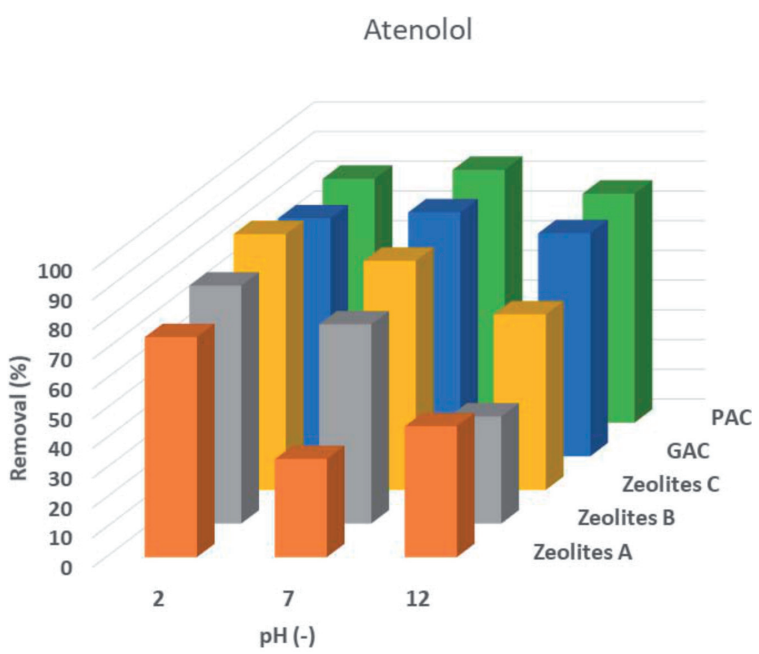

Fig. 3. Efficacy of atenolol removal on individual adsorbents at monitored $\mathrm{pH}$ values.

Another substance of interest in this group is caffeine. Caffeine is reported to have a high dipole moment, which increases with the polarity of the solution $[1,21,22]$. The neutral charge on the nitrogen atom interacts electrostatically with any negatively polarised functional group, and like that observed with atenolol, strongly positively charged caffeine ions are probably also capable of ion exchange in zeolites.

The results of our sorption test also showed a high elimination of caffeine on both types of activated carbon, which causes interactions of dipoles of caffeine molecules with n-electrons present on the adsorption surface [23]. Removal of this substance at $\mathrm{pH}=2.0$ ranged from $83 \%$ to more than $99 \%$ on all types of sorbents. In the medium $\mathrm{pH}$ range, the removal efficiency was from $25 \%$ to more than $99 \%$ at PAC. At $\mathrm{pH}=12.0$, caffeine removal was observed only at $25 \%-76 \%$. However, even at $\mathrm{pH}=12.0$, the specially treated PAC eliminated the substance by more than $99 \%$. Similarly high caffeine removal efficacies on clinoptilolitic sorbents were also achieved by Lelal et al. [24] and Martinez-Hernández et al. [25].

A third example of a base is carbamazepine. This drug cannot ionise at all, so at $\mathrm{pH}=7.0$, it behaves as a neutral compound, which has a significant effect on the sorption efficiency. In this case, it is necessary to be aware of the different adsorption properties of GAC and zeolites. This is because the adsorption force depends not only on the type of adsorbent but also, above all, on the mechanism by which the adsorption takes place. In the case of zeolites, where the sorption capacity is manifested mainly on ionic (dissociated) compounds, minimal efficiencies (in the range of $0 \%-14 \%$ ) of carbamazepine removal were observed at both $\mathrm{pH}=7.0$ and $\mathrm{pH}=12.0$ (in the range of $0 \%$ $12 \%)$. By changing the $\mathrm{pH}$ to a strongly acidic range $(\mathrm{pH}=2.0)$, the carbamazepine molecule was also slightly polarised, and removal efficiencies in the range of $17 \%-45 \%$ were observed. However, in the case of

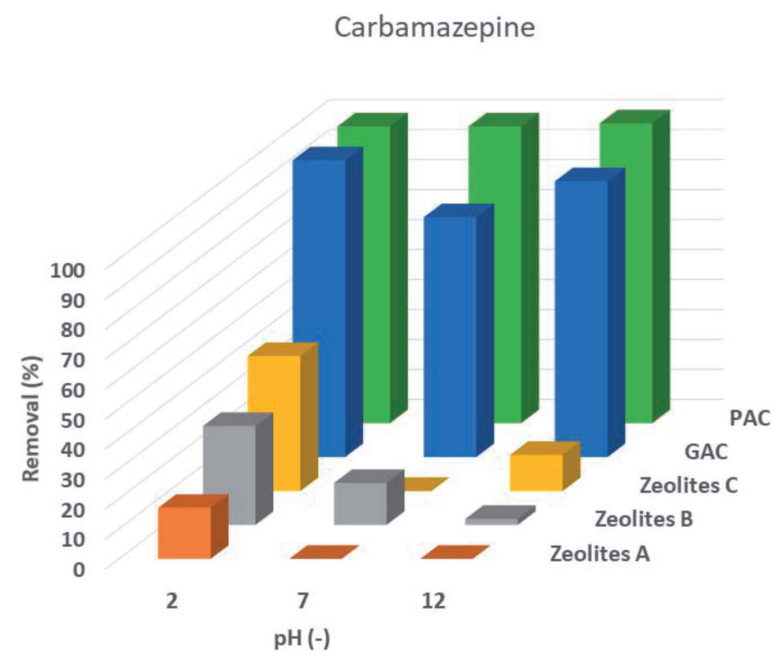

Fig. 4. Carbamazepine removal efficiencies for individual adsorbents at monitored $\mathrm{pH}$ values.

the use of activated carbon-based sorbents, removal efficiencies were significantly higher in the range of 80\%-99\% (GAC), resp. 99\%-100\% (PAC). This fact, as with other drugs investigated in the work, also confirms that the mechanisms of adsorption on zeolites and GAC (PAC) are significantly different.

Another group we can detect are substances that behave like acids. A good example is diclofenac. It is a polar molecule that additionally contains two bulky chlorine atoms. For adsorption, it is also necessary to consider the volume of the molecule, whether it can fit into the cavities of the adsorbent. Because of the value of $\mathrm{pKa}=4.15$ at $\mathrm{pH}=7.0$ and at $\mathrm{pH}=12.0$, deprotonation of the $-\mathrm{COOH}$ group to -COO- occurs, which makes the molecule negatively charged and thus tends to repel the surface charge of the adsorbent $[11,13]$. Therefore, the ion exchange reactions for zeolites were practically inefficient for all three fractions $(0 \%-27 \%)$. However,

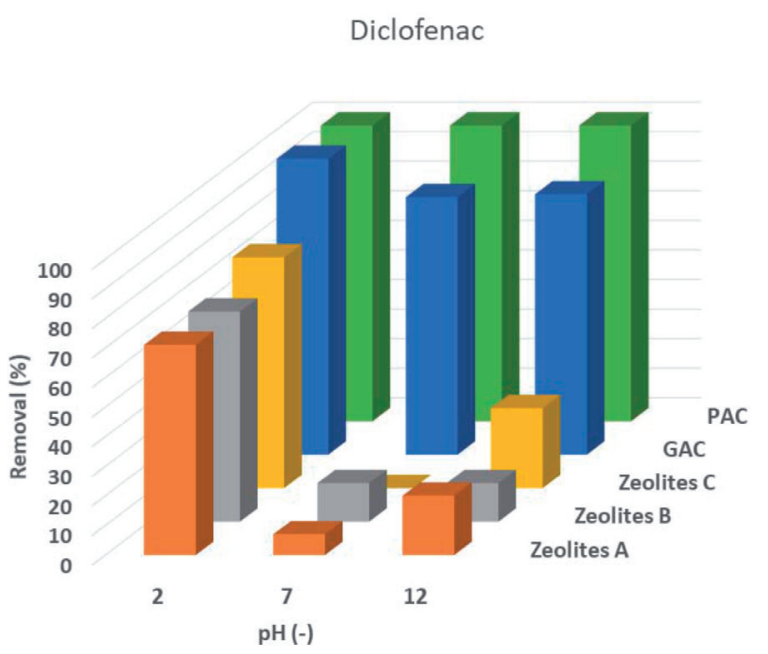

Fig. 5. Diclofenac drug removal efficiencies for individual adsorbents at monitored $\mathrm{pH}$ values. 
at $\mathrm{pH}=2.0$, when deprotonation did not take place, the sorption efficiency on zeolites was relatively high (71\%-78\%). However, deprotonation of diclofenac did not adversely affect sorption on both forms of activated carbon, where sorption efficiencies were above $90 \%$ at all $\mathrm{pH}$ values.

The last group of detected drugs in the outflow from the Devínska Nová Ves WWTP included substances called zwitterions. Such substances consist, for example, the antibiotic sulfamethoxazole (SMX). Its initial concentration was $43 \mathrm{ng} / \mathrm{l}$. The highest SMX removal efficiency was achieved at $\mathrm{pH}=2.0$, with PAC sorption medium. From the results, we can also state that the elimination of SMX at $\mathrm{pH}=2.0$ was extremely high for each sorption material. This fact is due to the influence of $\mathrm{pKa}$ value and $\mathrm{pH}$. According to a study by Kah et al. [11], SMX has two pKa values. The first value is when the drug behaves as a base pKal $=1.7$, and the second value is for the acid $\mathrm{pKa} 2=5.7$. At $\mathrm{pH}=2.0$, SMX behaves as a base and thus accepts a proton on the amino group and forms a cation. It is also true that the solubility of the neutral SMX molecule is much lower than that of the drug cation or anion. Sulfamethoxazole is a potent acceptor of $\pi$-electrons, which are provided by their amino functional groups (when protonated) and the N-heteroaromatic ring. The non-protonated sulfonamide group also has a high electron withdrawal capacity [11].

At medium $\mathrm{pH}$ (i.e. $\mathrm{pKa}$ (base) $<\mathrm{pH}<\mathrm{pKa}$ (acid)), SMX contains a small proportion of zwitterions in the aqueous phase. The relative stability of zwitterion is thought to be higher in the sorbed state than in the solution [26]. However, because of the very low proportion of zwitterions at medium $\mathrm{pH}$, charge interactions are expected to play only a minimal role in sorption.

The opposite phenomenon, i.e. a decrease in the sorption effect, was observed for SMX for $\mathrm{pH}=12.0$ when SMX behaves as an acid and thus a proton is

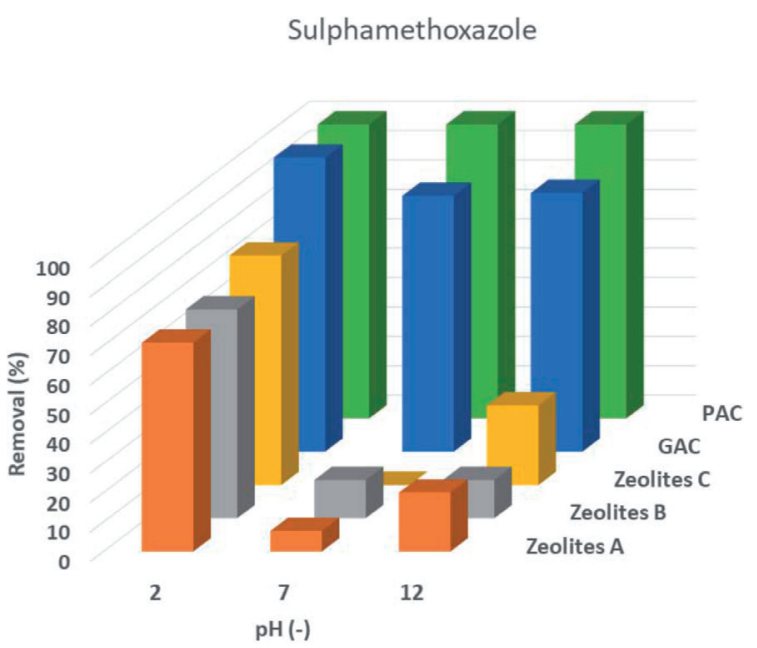

Fig. 6. Efficacy of sulfamethoxazole drug removal on individual adsorbents at monitored $\mathrm{pH}$ values. cleaved from the sulfonamide group and a free electron pair remains on the nitrogen. The surface charge of the sorbent is a key property of the sorbent that needs to be considered when investigating drug interactions. The presence of ionizable functional groups on the surface of many carbonaceous sorbents forces them to develop a surface charge that varies depending on the $\mathrm{pH}$ of the medium. The surface is positively charged at low $\mathrm{pH}$ and gradually becomes negatively charged with increasing $\mathrm{pH}$ (and acidic functional groups dissociate). If both the sorbate and the sorbent carry the same charge (usually at $\mathrm{pH}=12$ ), electrostatic repulsion is expected, but partial sorption can take place through ion bridging [11].

Elimination of sulfamethoxazole was up to $12 \%$ for zeolites A, B, and C. For PAC sorption material, sorption was still $>99 \%$. With GAC sorbent, elimination was zero. In this case, the $\mathrm{pH}-\mathrm{pKa} 2$ relationship applies, which indicates low drug sorption. In addition to the mechanisms proposed for acids, the decrease in sorption with increasing $\mathrm{pH}$ can be explained either by a decrease in electron-donor-acceptor (EDA) interactions (which decrease in the order cation $>$ neutral molecule $>$ anion) or by cation exchange (this only applies if zero charge (PZC) is less than the pKa for the base) [11].

Like SMX, sulfapyridine (SUL) belongs to substances called zwitterions. The originally measured concentration of SUL in treated wastewater from the Devínska Nová Ves WWTP was $240 \mathrm{ng} / \mathrm{l}$. As the $\mathrm{pH}$ decreased, the elimination efficiency increased with the use of all sorbents. Therefore, we can generally state that in zwitterions, substances behave as bases with decreasing $\mathrm{pH}$. They are strong acceptors of $\pi$-electrons. The solophobic effect decreases with the formation of cations [11].

Since these interactions are often donor-acceptor in nature, it is necessary to define these interactions in addition to Brønsted's theory of acids and bases, which rather describes the formation of charges in the drug molecule after proton transfer, as well as the Lewis theory of acids and bases. According to this theory, a base is any compound that is capable of being an electron pair donor, and an acid is any compound that is capable of being an electron pair acceptor. The Lewis theory better reflects some types of drug-adsorbent interactions.

\section{Conclusions}

The work deals with sorption tests with five types of sorbents, namely, three fractions of natural zeolites and granular and pulverised coal.

The treated wastewater from the Devínska Nová Ves WWTP was used as a sample, in which 102 drugs were detected, with a total concentration of 12,198.5 ng/l. The first experiment was performed at $\mathrm{pH}=7.0$. The results of this test show that the highest removal of the total drug concentration was observed in PAC, which 
is specially formulated to eliminate micropollutants from wastewater. Using zeolites, the highest removal efficiency of only $52 \%$ was achieved for zeolites C. From these results, we concluded that drug elimination was not sufficient at $\mathrm{pH}=7.0$; therefore, subsequent experiments were performed at $\mathrm{pH}=2.0$ and $\mathrm{pH}=12.0$, respectively.

After adjusting to $\mathrm{pH}=2.0$, the amount of drug removed in each of the sorbents used increased. Again, the highest efficacy was detected in PAC. In GAC, a $35 \%$ increase in total drug removal was observed. An increase in elimination was also observed for all zeolite fractions. From these data, we can state that adsorption at $\mathrm{pH}=2.0$ is more efficient than at $\mathrm{pH}=7.0$, which also follows from the literature data.

When comparing $\mathrm{pH}=12.0$ with $\mathrm{pH}=2.0$, we observed the opposite effect, and except for PAC, all substances were removed with minimal efficiency. The elimination decreased by almost $50 \%$ for all types of zeolite fraction and for GAC. At $\mathrm{pH}=12.0$, almost all drugs were above their $\mathrm{pKa}$ value. Therefore, our results confirm that if $\mathrm{pH}>\mathrm{pKa}$, sorption is less effective than in the case of $\mathrm{pH}<\mathrm{pKa}$.

\section{Acknowledgments}

This work was supported by the Slovak Research and Development Agency under the contracts No. APVV 0119-17. We would like to thank ProofreadingServices. com for proofreading the English language and the people from the Faculty of Fisheries and Protection of Waters, South Bohemian Research Center for Aquaculture and Biodiversity of Hydrocenoses, for their pharmaceuticals and drug analysis.

\section{Conflict of Interest}

The authors declare no conflict of interest.

\section{References}

1. KIECAK A., SASSINE L., BOY-ROURA M., ELSNER M., MAS-PLA J., LE GAL LA SALLE C., STUMPP C. Sorption properties and behaviour at laboratory scale of selected pharmaceuticals using batch experiments. Journal of Contaminant Hydrology, 225, 103500, 2019.

2. COMMISION EUROPEAN COMMISSION IMPLEMENTING DECISION (EU) 2018/840 of 5 June 2018, Official Journal of the European Union, 2018, March 2015, pp. 5-8.

3. VERLICCHI P., AL AUKIDY M., ZAMBELLO E. Occurrence of pharmaceutical compounds in urban wastewater: Removal, mass load and environmental risk after a secondary treatment-A review. Science of the Total Environment, 429, 123, 2012.

4. BODÍK I., MACKUL'AK T., FÁBEROVÁ M., IVANOVÁ L. Occurrence of illicit drugs and selected pharmaceuticals in Slovak municipal wastewater.
Environmental science and pollution research international, 23 (20), 21098, 2016.

5. MACKULAK T., BIROŠOVÁ L., GÁL M., BODÍK I., GRABIC R., RYBA J., ŠKUBÁK J. Wastewater analysis: the mean of the monitoring of frequently prescribed pharmaceuticals in Slovakia. Environmental monitoring and assessment, 188 (1), 18, 2016.

6. HU J., SHANG R., FROLOVA M., HEIJMAN B., RIETVELD L. Pharmaceutical adsorption from the primary and secondary effluents of a wastewater treatment plant by powdered activated carbon. Desalination and Water Treatment 57 (45), 21304, 2016.

7. RIZZO L., MALATO S., ANTAKYALI D., BERETSOU V.G., DOLIC M.B., GERNJAK W., HEATH E., IVANCEVTUMBAS I., KARAOLIA P., RIBEIRO L., MASCOLO G., MCARDELL C.S., SCHAAR H., SILVA A.M.T., FATTA-KASSINOS D. Consolidated vs new advanced treatment methods for the removal of contaminants of emerging concern from urban wastewater. Science of the Total Environment 655, 986, 2019.

8. EGGEN R.I.L., HOLLENDER J., JOSS A., SCHÄRER M., STAMM CH. Reducing the Discharge of Micropollutants in the Aquatic Environment: The Benefits of Upgrading Wastewater Treatment Plants. Environmental Science and Technology 48, 7683, 2014.

9. BIMOVÁ P., ROUPCOVÁ P., KLOUDA K., MATĚJOVÁ L., VOJS STAŇOVÁ A., GRABICOVÁ K., GRABIC R., MAJOVÁ V., ŠPALKOVÁ V., GEMEINER P., CELEC P., KONEČNÁ B., BÍROŠOVÁ L., KRAHULCOVÁ M., MACKULAK T. Biochar - An efficient sorption material for the removal of pharmaceutically active compounds, DNA and RNA fragments from wastewater. Journal of Env. Chem. Eng. 9, 1057462021.

10. ZHENG L., PeENG D., ZHANG S., YANG Y., ZHANG L., MENG P. Adsorption of sulfamethoxazole and sulfadiazine on phosphorus-containing stalk cellulose under different water $\mathrm{pH}$ studied by quantitative evaluation. Environmental Science and Pollution Research 27, 43246, 2020.

11. KAH M., SIGMUND G., XIAO F., HOFMANN T. Sorption of ionizable and ionic organic compounds to biochar, activated carbon and other carbonaceous materials. Water Research, 124, 673, 2017.

12. BUI T.X., CHOI H. Adsorptive removal of selected pharmaceuticals by mesoporous silica SBA-15. Journal of Hazardous Materials, 168 (2), 602, 2009.

13. OH S., SHIN W.S., KIM H.T. Effects of $\mathrm{pH}$, dissolved organic matter, and salinity on ibuprofen sorption on sediment. Environmental Science and Pollution Research, 23 (22), 22882, 2016.

14. MARTUCCI A., PASTI L., MARCHETTI N., CAVAZZINI A., DONDI F., ALBERTI A. Adsorption of pharmaceuticals from aqueous solutions on synthetic zeolites. Microporous and Mesoporous Materials, 148 (1), 174, 2012.

15. BOHINC T., HORVAT A., ANDRIĆ G., GOLIĆ M.P., KLJAJIĆ P., TRDAN S. Natural versus synthetic zeolites for controlling the maize weevil (Sitophilus zeamais)like Messi versus Ronaldo? Journal of Stored Products Research, 88, 101639, 2020.

16. ZEOCEM A.S. Čo je Zeolit - Klinoptilolit. Retrieved March 20, 2019, from https://www.zeocem.com/sk/zeolit, 2016.

17. BANSAL R., GOYAL M. Activated carbon adsorption. USA: Taylor \& Francis, 2005.

18. FEDOROVA G., RANDAK T., LINDBERG R.H., GRABIC R. Comparison of the quantitative performance 
of a Q-Exactive high-resolution mass spectrometer with that of a triple quadrupole tandem mass spectrometer for the analysis of illicit drugs in wastewater. Rapid Communications in Mass Spectrometry, 27 (15), 1751, 2013.

19. CIRJA M., IVASHECHKIN P., SCHÄFFER A., CORVINI P.F.X. Factors affecting the removal of organic micropollutants from wastewater in conventional treatment plants (CTP) and membrane bioreactors (MBR). Reviews in Environmental Science and Biotechnology, 7 (1), 61, 2008.

20. NEWTON D.W., KLUZA RB. pKa values of medicinal compounds in pharmacy practice. Drug Intelligence and Clinical Pharmacy, 12 (9), 546, 1978.

21. BENJAMINE A.A., LUCIE B.A., DENIS Y.K., SAWALIHO B.E.H. Structures, Lipophilicity, Dipole Moments, Acidity and Spectroscopic Properties of NonSteroidal Anti-Inflammatory Drugs Diclofenac, Bromfenac and Amfenac: A Theoretical Study. Computational Chemistry, 07 (04), 95, 2019.

22. YAMAMOTO K., SHIONO T., MATSUI Y., YONEDA M. Interaction of caffeine with montmorillonite. Particulate Science and Technology, 37 (3), 325, 2019.
23. RIGUETO C.V.T., NAZARI M.T., DE SOUZA C.F., CADORE J.S., BRIÃO V. B., PICCIN J.S. Alternative techniques for caffeine removal from wastewater: An overview of opportunities and challenges. Journal of Water Process Engineering, 35, 101231, 2020.

24. LEAL M., MARTÍNEZ-HERNÁDEZ V., MEFFE R., LILLO J., DE BUSTAMENTE I. Clinoptilolite and palygorskite as sorbents of neutral emerging organic contaminants in treated wastewater: Sorption-desorption studies. Chemosphere 175, 534, 2017.

25. MARTINEZ-HERNÁNDEZ V., MEFFE R., HERRERA S., ARRANZ E., DE BUSTAMENTE I. Sorption/desorption of non-hydrophobic and ionisable pharmaceutical and personal care products from reclaimed water onto/from a natural sediment. Science of the Total Environment 472, 273, 2014.

26. TEIXIDÓ M., PIGNATELLO J.J., BELTRÁN J.L., GRANADOS M., PECCIA J. Speciation of the ionizable antibiotic sulfamethazine on black carbon (Biochar). Environmental Science and Technology, 45 (23), 10020, 2011. 